\title{
Lifestyle, Biological Risk Markers, Morbidity and Mortality in a Cohort of Men 33 - 42 Years Old at Baseline, after 24-Year Follow-Up of a Primary Health Care Intervention
}

\author{
Lars-Göran Persson ${ }^{1}$, Hans Lingfors ${ }^{1}$, Mats Nilsson², Sigvard Mölstad ${ }^{3}$ \\ ${ }^{1}$ Health Care Centre of Habo and Unit for Research and Development in Primary Health Care, Futurum, \\ Jönköping, Sweden \\ ${ }^{2}$ Futurum County Council of Jönköping, Jönköping, Sweden \\ ${ }^{3}$ Department of Clinical Sciences, General Practice, Lund University, Malmö, Sweden \\ Email: "Lars-goran.persson@ril.se
}

Received 6 February 2015; accepted 10 March 2015; published 13 March 2015

Copyright $@ 2015$ by authors and Scientific Research Publishing Inc.

This work is licensed under the Creative Commons Attribution International License (CC BY).

http://creativecommons.org/licenses/by/4.0/

(c) (i) 0 pen Access

\section{Abstract}

Objective: To study changes in lifestyle and biological risk markers in a 24-year follow-up study, and occurrences of cardiovascular diseases (CVD), cancer and total mortality from official registers. Design: A 24-year follow-up survey and register study of a cohort of men $33-42$ years old, examined with a health profile at baseline. With the health profile based on lifestyle, biological risk markers, self-rated mental stress and mental health, the men were separated in different risk groups. Setting: Primary health care center of Habo in Sweden. Subjects: All 757 men, 33 - 42 years old, and living in the community of Habo in Sweden in 1985. Main Outcome Measures: Lifestyle, biological risk markers, morbidity from CVD and cancer, and total mortality. Results: Smoking and physical activity decreased during follow-up time while alcohol consumption increased. Biological risk markers, except diastolic blood pressure, deteriorated significantly with age. Based on threelifestyle groups, $16 \%$ of the men had a more favorable lifestyle and $19 \%$ had a less favorable lifestyle at follow-up compared with baseline. The men, who had been classified as high-risk, based on the health profile at baseline, had a significantly higher incidence of CVD and cancer in the register study compared to men in a low-risk group. The baseline non-participant group had a significantly higher incidence of CVD and a higher mortality compared to the low-risk group. Conclusion: A health profile with a combination of lifestyle factors and biological risk markers can already at

${ }^{*}$ Corresponding author. 
the age of 33 - 42 years predict incidence of CVD and cancer on group level among men after 24 years.

\title{
Keywords
}

\author{
Lifestyle, Primary Health Care, Health Dialogue, Primary Prevention
}

\section{Introduction}

Cardiovascular disease (CVD) is the most common cause of total mortality and premature death (before 75 years of age) in Sweden as well as in other Western countries [1] [2]. However during the period 1997 up to 2012 premature mortality in myocardial infarction has decreased with approximately $50 \%$ in Sweden and most western countries [3]. According to the INTERHEART study, more than $90 \%$ of the risk for acute myocardial infarction could be explained by nine modifiable risk factors, most of them being lifestyle factors [4]. The same factors in addition to cardiac disease were associated to $90 \%$ of stroke [5]. Lifestyle is also related to risk for cancer [6] [7]. In a Swedish study non-smoking, moderate physical activity and minor alcohol consumption together with four healthy dietary habits could identify 60-year-old men and women with substantially lower risk for CVD and death [8].

Some kind of global risk assessment is recommended to estimate the risk for future death in CVD. SCORE (Systematic Coronary Risk Evaluation) is one such risk assessment system, developed by the European Society of Cardiology and modified for use in Sweden [9] [10].

Another kind of risk assessment tool, a pedagogic health profile, was developed and used in a primary prevention programme for men, 33 - 42 years of age, in the community of Habo in Sweden [11]. Each of 10 risk factors considered being most important for CVD and cancer was graded in 4 or 5 levels. This health profile was used in a health dialogue with a specially trained nurse. In that study a rather thorough examination of the nonparticipants was done [11].

An improved health profile called "Health Curve" was later used in a health promotion programme for both men and women 30 and 35 years of age called "Live for Life" where community efforts were combined with a health dialogue with a nurse [12]. In the Health Curve dietary habits concerning fat and fiber intake were measured using a pedagogic food frequency questionnaire [13].

Rather few studies concerning cohorts of men with a follow-up time of more than 20 years have been published. The study of British doctors, the Whitehall study and the Oslo study are such examples [14]-[16]. The 50-year follow-up of the male British doctors showed a progressive decrease in mortality rates among non-smokers in relation to continuous smokers, and that smoking cessation in different ages could add years to life expectancy [14]. On group level the continuous smokers lost 10 years of life. In the Whitehall study with 38-year follow-up time, there was a risk core based on smoking, diabetes, employment grade, blood pressure, serum cholesterol, and Body Mass Index (BMI) Men in the highest 5\% risk score had a 15 year shorter life expectancy compared with those in the lowest $5 \%$ risk score [15]. The Oslo study was a primary prevention intervention study of men focused on lifestyle, especially smoking and dietary habits. The 28-year follow-up showed a decrease of leisure time physical activity (LTPA), and that LTPA had an independent predictive association with metabolic syndrome [16].

In studies with long-term follow-up the study population is generally 40 years and older at baseline. There are some examples of studies where the study population is younger than 40 years at baseline [17]-[19]. The 21-year follow-up of the Cardiovascular Risk in Young Finns Study showed an increase in BMI, serum triglycerides and a decrease in blood pressure and serum cholesterol [17]. The men in Chicago Heart Association Detection Project in Industry study were 18 to 39 years at baseline [18]. In this study blood pressure above normal was significantly related to increased mortality due to CVD and all causes. The men in three large cohorts study were also 18 to 39 years at baseline [19]. The results from this study could show a graded relationship of serum cholesterol to longterm risk of CVD and all-cause mortality.

To our knowledge no studies on a cohort of men as young as in our study have been organized and carried out in primary care with a follow-up time of more than 20 years.

This 24-year follow-up survey and register study was done on all men 33 - 42 years old at baseline in the 
community of Habo in Sweden.

There are four aims of this study:

- To study if a long-term follow-up of men in a rather young age group at baseline, can be organized and carried out in primary health care with a high participation rate.

- To measure long-time changes, after approximately 24 years of follow-up, in lifestyle and biological risk markers for men taking part in the primary prevention programme in the community of Habo between 1985 and 1987.

- To study the association between food habits and a healthy lifestyle concerning physical activity, smoking and alcohol consumption, and the association between self-rated health and the different risk groups.

- To study morbidity from CVD, cancer and total mortality, on defined high- and low risk groups and nonparticipants in the whole baseline cohort of 757 men.

\section{Methods}

\subsection{Baseline Survey}

All 757 men in the community of Habo aged 33 - 42 years in 1985 were invited to a health examination and a health dialogue with a specially trained nurse [11]. The health examination was done during the years 1985-1987. A pedagogic health profile, with 10 risk factors considered being most important for CVD and cancer were classified in 4 or 5 levels, was used during this health dialogue Table 1.

\section{Explanations}

Heredity death: Highest risk point for father or mother registered (except for accidents or infections).

LTPA: 1 means regular hard physical training and competition, 4 means physically inactive leisure time [20]. Mental stress: Visual analogue scale, mm (0 - 100).

Mental health: According to judgement by nurse. 1 means good mental health, 4 means need of group therapy with muscular relaxation and 5 means need for individual contact with a doctor or a psychologist.

Arterial blood pressure: Highest risk point for systolic or diastolic blood pressure registered. Different values for men under 40 years or $\geq 40$ years old.

The intention with the health profile was that the men should get a better understanding of the risk factors and the relation between the risk factors. At baseline the 652 men (participation rate 86\%) who attended were grouped

Table 1. Health profile showing limits for classification into different risk groups (risk points).

\begin{tabular}{|c|c|c|c|c|c|}
\hline \multirow{2}{*}{ Risk faktors studied } & \multicolumn{5}{|c|}{ Risk points } \\
\hline & 1 & 2 & 3 & 4 & 5 \\
\hline Age (yrs) at death of father & $\geq 95$ & $70-94$ & $60-69$ & $50-59$ & $<50$ \\
\hline Age (yrs) at death of mother: & $\geq 95$ & $75-94$ & $65-74$ & $55-64$ & $<55$ \\
\hline Number of diabetics among parents or siblings & - & - & - & 1 & $\geq 2$ \\
\hline Use of alcohol (g per week) & 0 & $1-49$ & $50-109$ & $110-249$ & $\geq 250$ \\
\hline Smoking (cig/day) & 0 & Ex. smoker & $1-14$ & $15-24$ & $\geq 25$ \\
\hline LTPA (self-estimation) & 1 & 2 & 3 & 4 & - \\
\hline Mental stress (self-estimation) & $<40$ & $40-69$ & $70-89$ & $\geq 90$ & - \\
\hline Mental health (estimation by nurse) & 1 & 2 & 3 & 4 & 5 \\
\hline BMI (kg/m²) & $<20$ & $20-24$ & $25-29$ & $30-39$ & $\geq 40$ \\
\hline Blood pressure $(\mathrm{mmHg})<40$ years & $\leq 140 /<85$ & $>140 />85$ & $>155 />90$ & $>160 />95$ & $>170 />105$ \\
\hline Bloodpressure $(\mathrm{mmHg}) \geq 40$ years & $\leq 150 /<90$ & $>150 />90$ & $>160 />95$ & $>170 />95$ & $>180 />115$ \\
\hline Serum cholesterol (mmol/l) & $<4.6$ & $4.6-5.9$ & $6.0-7.7$ & $7.8-9.5$ & $\geq 9.6$ \\
\hline
\end{tabular}


into a high-risk and a low-risk group depending of risk points in the health profile. The risk factors used for this grading were three lifestyle factors smoking; alcohol consumption and LTPA, the biological risk markers BMI, blood pressure and serum cholesterol, as well as self-estimated mental stress and mental health. Family risk factors were not used in this grading.

The classification of the high-risk group was based on two criteria:

1) All men with at least one risk factor with risk point 4 or 5 except smoking and LTPA. 2) All men with at least 4 factors with risk point 3 . The rest were classified as low-risk group. With these criteria 292 men were classified as high-risk group and 360 men as low-risk group. All 292 men in the high-risk group were advised to see a doctor for further discussion about the risk factors and how to lower these. The doctor decided on clinical judgment if complementary test and pharmacological treatment were to be recommended.

Participants were also grouped according to lifestyle summarized risk points in the health profile for smoking, LTPA and alcohol consumption. In the baseline examination there were 115 men with a favorable lifestyle (3 - 5 risk points), 270 men in the middle group (6 - 8 risk points) and 96 men in the group with least favorable lifestyle (9 - 14 risk points). None in the healthy lifestyle group was a smoker at baseline.

Special intervention programs for men with elevated risk factors were carried out in the primary health care center and concerning physical inactivity in cooperation with local clubs. Altogether 418 of the 652 men who attended the health dialogue were recommended some kind of preventive measure. An oral glucose tolerance test was done on all 170 men, who reported a family history of diabetes and/or had a BMI $\geq 27$ [21].

Intervention programs in the health care center were smoking cessation groups and dietary education in groups. More details about the grading of the health profile, questionnaire, intervention programme, anthropometric measurements and blood tests have been described earlier [11] [22]. Men in the high-risk group, who had been to the consultation with the doctor, were also invited to a 1-year follow-up, where 161 men attended.

\subsection{Follow-Up Survey}

A new health dialogue and examination of the men was carried out during 2009-2010 after a mean follow-up time of 24 years. Due to lack of financial and personnel resources, a selection had to be made. Only those who were still living in the community of Habo or in the neighboring communities were invited to the new health examination. From the baseline high-risk group, all those who attended the 1-year follow-up (141 men) were invited, as were 155 men (every second on the list) from the low-risk group.

Those who were not invited and those who declined to participate in the new health examination were sent the same health and food frequency questionnaires [13] as those who accepted the invitation and attended. They were asked to measure body weight, height, waist and hip circumference at home after an illustrated instruction. The invitations were sent from Statistics Sweden in order to get correct addresses. A flow chart shows the different groups in the baseline and follow-up examinations Figure 1.

\subsubsection{Questionnaire}

The questions in the new questionnaire used in the follow-up study were to a great extent the same as in the baseline questionnaire. A new food frequency questionnaire, measuring the intake of saturated and trans fats and fiber, which had been used in the "Live for life" health promotion programme, was added [12] [13]. The new health questionnaire included questions about lifestyle, psychosocial exposure, self-rated health, mental stress as well as own and family history of cardiovascular disease, hypertension and diabetes. The participants were also asked to specify which regular medication they were using.

\subsubsection{Examinations}

The anthropometric measurements and peak expiratory flow (PEF) were done in the same way as in the initial health examination [11]. Blood samples, taken in the seated position with a minimal stasis, were sent to and analyzed in the clinical chemistry laboratory in the county hospital of Jönköping. Serum cholesterol, triglycerides, S-HDL-cholesterol, and P-glucose were analyzed with an enzymatic method using the instrument ADVIA-1800 from Siemens. S-LDL cholesterol was calculated according to Friedewalds formula.

\subsubsection{Health Dialogue}

All men attending the examination had a health dialogue with a specially trained nurse. The main issue was how to 


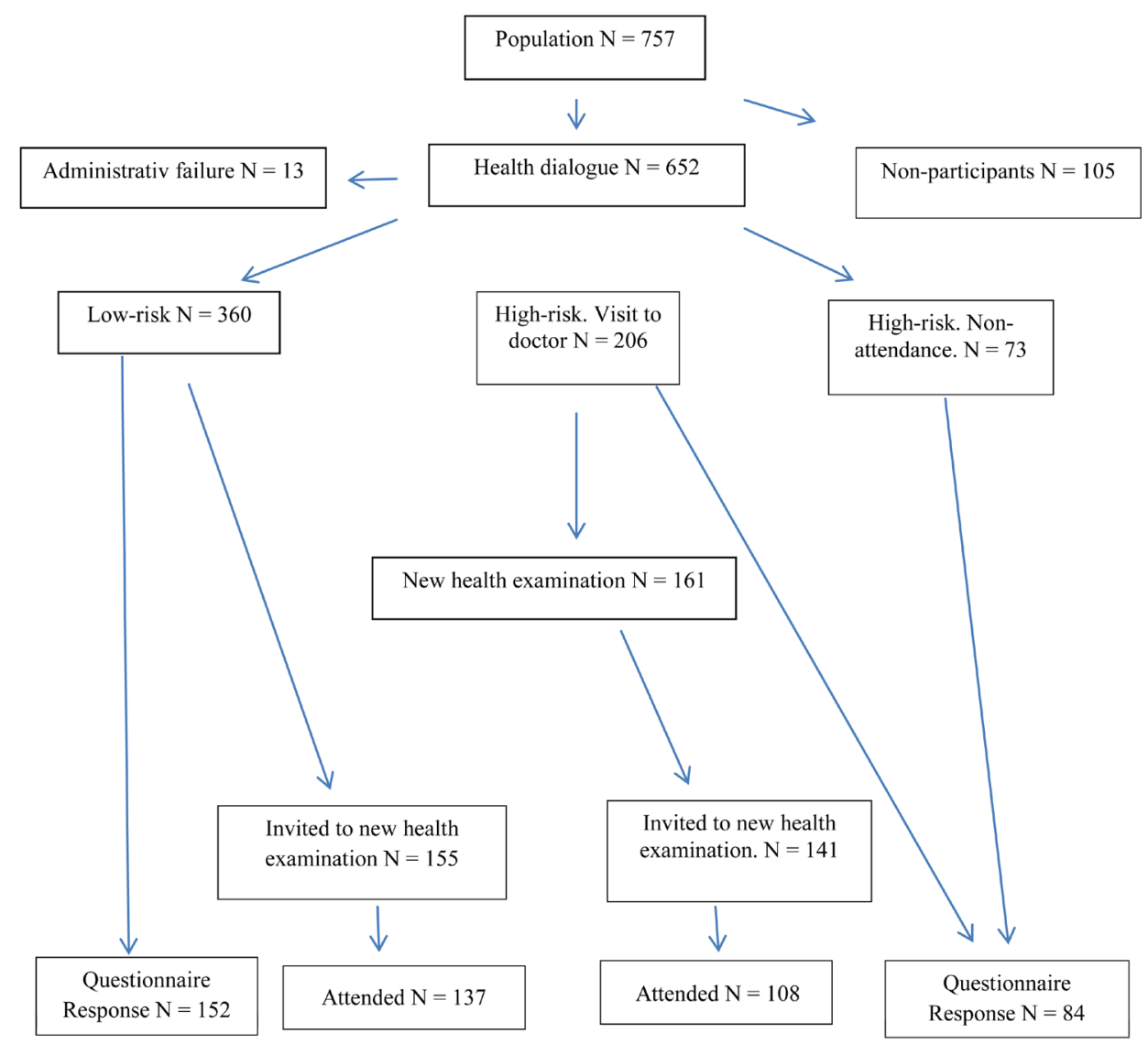

Figure 1. Flow chart showing the different groups in the baseline and follow-up examinations.

improve lifestyle in a patient centered way. The men were also given a short brochure about healthy lifestyle and its positive influence on health, diseases and life expectancy. A doctor studied the questionnaires and blood tests and decided if complementary tests were indicated. A letter was sent to all men about the results of the measurement and blood tests and with further advice about lifestyle, and complementary blood tests.

\subsection{Comparisons Made between Baseline and Follow-Up Surveys}

- Separate lifestyle factors smoking, alcohol consumption and LTPA.

- Combination of lifestyle factors in groups.

- Biological risk markers weight, BMI, waist and hip circumferences, waist to hip ratio (WHR), systolic and diastolic blood pressure, serum lipids, blood glucose and PEF.

\subsection{Register Study}

All males who developed CVD, cancer or died were grouped into the high or low-risk groups of participants and non-participants respectively from the baseline study in 1985-1987 ( $\mathrm{N}=757)$. Data were gathered from health-care registers at the Swedish National Board of Health and Welfare. Data from these registers were available up to 2010. ICD-9 diagnoses from 1987-1996 were 410, 431, 432, 434-36. ICD-10 diagnoses from 1997 were I21, I22, I61, I63, I64, G45 and FN. All cancer diagnoses were grouped together. Two groups were formed: Those with at least one CVD diagnose, or cancer diagnoses and those without such diagnose.

\subsection{Statistical Methods}

Differences between continuous variables like biological risk markers were tested with paired or unpaired t-test. Lifestyle variables were tested with sign test, Wilcoxon and Kruskal-Wallis test. Changes in lifestyle risk points 
were analyzed with a rank-invariant non-parametric method [23]. Self-rated health was analysed in relation to lifestyle, for high and low-risk group with Chi-Square test and trends with Mantel-Haenszel Chi-Square test. Suitable statistical software has been used for the analysis.

\section{Results}

\subsection{Participation}

During the new health survey, 108 men from the baseline high-risk group (participation rate 77\%), and 137 men from the low-risk group (participation rate 88\%) attended. The overall participation rate was $83 \%$. Among those not invited to the health examination, 84 men in the high-risk group and 152 men in the low-risk group responded to the questionnaire (54\% and 75\% respectively) Figure 1.

Overall, 192 men in the baseline high-risk group and 289 men in the low-risk group responded to the questionnaires in the follow-up study.

\subsection{Lifestyle and Self-Rated Health}

Comparing lifestyle for all men, the time trend shows that smoking had decreased $(p<0.001)$. Of the 131 men (28\%) who were smokers at baseline, 81 had quit. At follow-up $10 \%$ were daily smokers. The average alcohol consumption had increased from $12.6 \mathrm{cl} /$ week to $22.1 \mathrm{cl} /$ week $(p<0.001)$. LTPA had decreased $(p<0.001)$.

At baseline 92 men (48\%) were smokers in the high-risk group and 39 men (13\%) in the low-risk group. At follow-up 37 men (19\%) were smokers in the high-risk group and 14 men (5\%) smokers in the low-risk group. The alcohol consumption was significantly higher in the high-risk group ( $28 \mathrm{cl} /$ week compared to $18 \mathrm{cl} /$ week). LTPA was higher in the low-risk group, but there was no statistically significant difference.

An Analysis was done if there had been a shift between the three lifestyle groups from baseline to follow-up Figure 2 and Figure 3.

This analyze showed that several men had changed lifestyle risk group and moved from a less favorable to a more favorable group and vice versa. Seventy-five men (16\%) had improved their lifestyle from baseline and shifted to a more favorable lifestyle group. Ninety-fourmen (19\%) had shifted to a less favorable lifestyle group, while 312 men (65\%) belonged to the same lifestyle group booth at follow-up and baseline.

A healthy lifestyle concerning smoking, LTPA and alcohol consumption was also significantly associated $(p<$ 0.001 ) with better food habits concerning fat and fiber intake measured with the food frequency questionnaire [13].

Self-rated health is an important predictor for future morbidity and mortality. In the questionnaire there was a question where the participants could classify their perceived health into five different levels from excellent to bad. The 192 men in the high-risk group at follow-up estimated their health less favorable than men in the low-risk

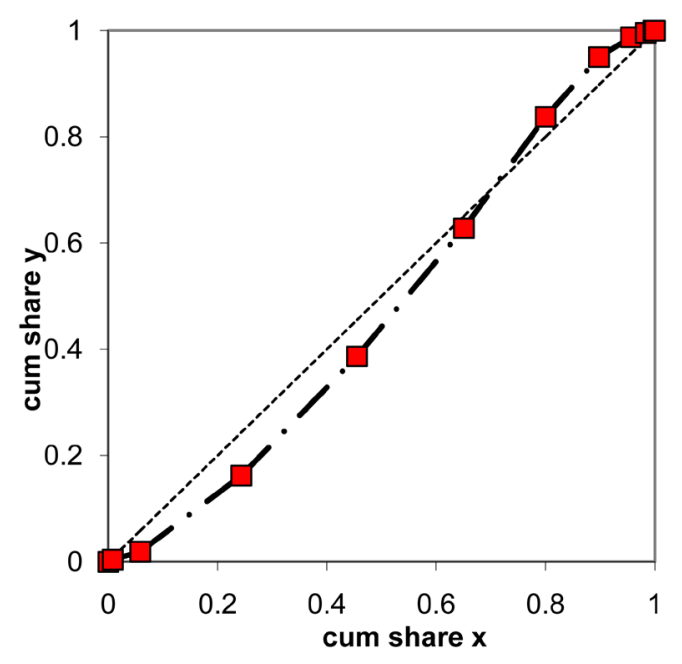

Figure 2. Relation between summarized lifestyle risk points during baseline and follow-up examinations [23]. 


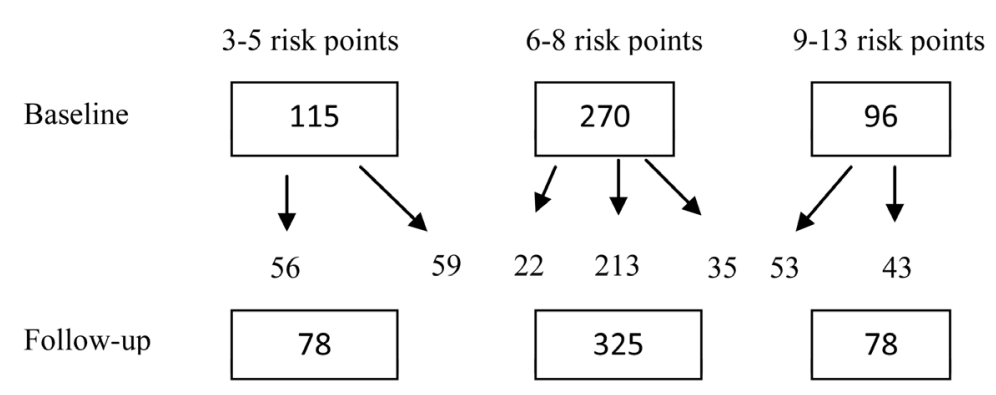

Figure 3. Summarized risk points for lifestyle (smoking, LTPA and alcohol consumption) for baseline and follow-up, number of men in the lifestyle groups and how individuals have changed between risk groups.

group $(p<0.001)$. There was also a significant trend $(p<0.01)$ at follow-up for those exhibiting a more favorable lifestyle to estimate their health to be better compared with those with a less favorable lifestyle.

\subsection{Biological Risk Markers}

The baseline and follow-up variables for biological risk markers were compared for the whole group of participants and questionnaire responders Table 2.

Nurses did anthropometric measurements on the participants in the follow-up survey, and from those who were not invited there were self-reported values in the questionnaires. With the exception of diastolic blood pressure, which was significantly lower during follow-up, all other measurements had deteriorated.

Follow-up survey variables for baseline low-risk and high-risk groups were compared Table 3.

In the baseline high-risk group most of the biological risk markers were significantly higher at the follow-up than in the low-risk group except for serum cholesterol and PEF. Medication for high serum cholesterol was used by $19 \%$ in the high-risk group and by $9 \%$ in the low-risk group.

\subsection{Morbidity and Mortality}

There were no significant differences between the three different baseline lifestyle groups concerning questionnaire reported hypertension, diabetes, cardiovascular diseases or cancer at follow-up. The baseline high-risk group reported significantly more cancer, hypertension and diabetes than the baseline low-risk group at follow-up.

In the registers from the Swedish National Board of Health and Welfare there were significantly more CVD among the baseline high-risk and non-participant groups than in the low-risk group Table 4.

The total number of cancer was higher in the baseline high-risk group than in the low-risk group. The mortality rate was significantly higher in the baseline non-participant group in comparison with the low-risk group. Almost $7 \%$ of the whole cohort had died during follow-up time.

\section{Discussion}

The overall participation rate of $83 \%$ of those who were invited to a new health dialogue and health examination was high. In the 28-year follow-up of the Oslo study the participation was 62\% [16]. The men in the Oslo study were 40 - 49 years old at baseline. Only men living in Oslo and Akershus were invited to follow-up. It is comparable to our study where only men still living in Habo and neighboring communities were invited.

The most positive change in lifestyle factors was smoking cessation with a decrease from $27 \%$ to $10 \%$. The decreasing proportion of smokers is similar to the national Swedish trend and figures from Statistics Sweden, although the prevalence of 10\% daily smokers at follow-up in our study is lower. In Sweden in 1985 36\% of men in age group 36 - 40 years were daily smokers, and in 2010-2011 18\% of men in age group 55 - 64 years were daily smokers. In comparison with the initial examination, alcohol consumption had increased from a rather low level and LTPA had decreased. Self-rated health has in several studies been a good predictor for future morbidity and mortality [24] [25]. In our study the low-risk group and those with favorable lifestyle estimated their health more positively.

The biological risk factors, except for diastolic blood pressure had deteriorated significantly for the entire co- 
Table 2. Comparisons of biological risk markers at baseline and follow-up for all men in the follow-up survey.

\begin{tabular}{|c|c|c|c|c|c|c|}
\hline & \multirow{2}{*}{$\mathbf{N}$} & \multicolumn{2}{|c|}{ Baseline } & \multicolumn{2}{|c|}{ Follow-up } & \multirow{2}{*}{ Significance } \\
\hline & & Mean & SD & Mean & SD & \\
\hline Weight (kg) & 477 & 77.96 & 9.90 & 85.17 & 12.13 & $* * *$ \\
\hline BMI (kg/m²) & 477 & 24.37 & 2.73 & 26.96 & 3.48 & $* * *$ \\
\hline Waist (cm) & 423 & 90.03 & 7.57 & 99.35 & 9.64 & $* * *$ \\
\hline Hip (cm) & 423 & 100.96 & 5.44 & 103.61 & 6.38 & $* * *$ \\
\hline WHR & 423 & 0.89 & 0.04 & 0.96 & 0.06 & $* * *$ \\
\hline Systolicbloodpressure (mmHg) & 245 & 135.37 & 11.96 & 144.96 & 16.88 & $* * *$ \\
\hline Diatolicbloodpressure (mmHg) & 245 & 87.15 & 8.11 & 85.41 & 8.89 & $* *$ \\
\hline Serum cholesterol (mmol/l) & 245 & 5.38 & 1.08 & 5.83 & 1.08 & $* * *$ \\
\hline Serum triglycerides (mmol/l) & 245 & 1.82 & 1.25 & 2.26 & 1.34 & $* * *$ \\
\hline Blood glucose (mmol/l) & 245 & 5.28 & 1.03 & 5.94 & 1.71 & $* * *$ \\
\hline PEF & 205 & 612.3 & 73.64 & 557.4 & 77.22 & $* * *$ \\
\hline
\end{tabular}

${ }^{* *} p<0.01,{ }^{* * *} p<0.001$ follow-up values compared with baseline values. Registrations for waist, hip, WHR, PEF were not complete during the first examination. Some questionnaire responders did not report their anthropometric measurements. During follow-up only those who took part in the health examination had measurements for blood pressure and serum lipids.

Table 3. Comparison of biological risk markers for baseline low- and high-risk groups at follow-up.

\begin{tabular}{|c|c|c|c|c|c|c|c|}
\hline & \multicolumn{3}{|c|}{ Low-risk group } & \multicolumn{3}{|c|}{ High-risk group } & \multirow{2}{*}{ Significance } \\
\hline & $\mathbf{N}$ & Mean & SD & $\mathbf{N}$ & Mean & SD & \\
\hline Weight (kg) & 286 & 83.06 & 10.18 & 191 & 88.34 & 14.01 & $* * *$ \\
\hline BMI $\left(\mathrm{kg} / \mathbf{m}^{2}\right)$ & 286 & 26.25 & 2.83 & 191 & 28.03 & 4.06 & $* * *$ \\
\hline Waist (cm) & 284 & 97.43 & 8.24 & 190 & 102.48 & 10.87 & $* * *$ \\
\hline Hip (cm) & 284 & 102.75 & 5.74 & 190 & 104.91 & 7.21 & $* * *$ \\
\hline WHR & 284 & 0.95 & 0.06 & 190 & 0.98 & 0.06 & $* * *$ \\
\hline Systolicblood pressure (mmHg) & 137 & 142.89 & 16.23 & 108 & 147.58 & 17.38 & $*$ \\
\hline Diatolicblood pressure (mmHg) & 137 & 84.39 & 8.83 & 108 & 86.69 & 8.85 & * \\
\hline Serum cholesterol (mmol/l) & 137 & 5.87 & 1.12 & 108 & 5.77 & 1.03 & \\
\hline Serum triglycerides (mmol/l) & 137 & 2.06 & 1.01 & 108 & 2.52 & 1.63 & $* *$ \\
\hline Bloodglucose (mmol/l) & 137 & 5.74 & 1.19 & 108 & 6.19 & 2.18 & $*$ \\
\hline PEF & 136 & 560.48 & 76.44 & 107 & 548.60 & 81.84 & \\
\hline
\end{tabular}

${ }^{*} p<0.05,{ }^{* *} p<0.01,{ }^{* * *} p<0.001$ values for high-risk group compared with low-risk group. Registrations for waist, hip, WHR, PEF were not complete during the first examination. Some questionnaire responders did not report their anthropometric measurements. During follow-up only those who took part in the health examination had measurements for blood pressure and serum lipids.

hort and especially for the high-risk group. The fact that serum cholesterol was not higher in the high-risk group could be explained by differences in lipid lowering medication. Medication for high serum cholesterol was used by $19 \%$ in the high-risk group and by $9 \%$ in the low-risk group. The change and deterioration of most biological risk markers is similar to men in the Whitehall study [26]. A study in Gothenburg of risk factors in a group of men 50 years old and another group of men 60 years old showed impaired anthropometric data, blood pressure, but not serum lipids among the older men [27]. 
Table 4. Numbers of CVD, cancer and total mortality in the baseline low-risk, high-risk and nonparticipant groups, together with Odds ratio and confidence intervals. Comparisons were made with baseline low-risk group.

\begin{tabular}{|cccccccccccc}
\hline Risk group & N & $\begin{array}{c}\text { Number } \\
\text { of CVD }\end{array}$ & $\begin{array}{c}\text { Odds } \\
\text { ratio }\end{array}$ & CI & $\begin{array}{c}\text { Number } \\
\text { of cancer }\end{array}$ & $\begin{array}{c}\text { Odds } \\
\text { ratio }\end{array}$ & CI & $\begin{array}{c}\text { Number } \\
\text { of dead }\end{array}$ & $\begin{array}{c}\text { Odds } \\
\text { ratio }\end{array}$ & CI \\
\hline Low-risk & 360 & 26 & 1.0 & & 29 & 1.0 & & 14 & 1.0 & \\
High-risk & 292 & 41 & 2.1 & $1.21-3.64$ & 48 & 2.25 & $1.34-3.77$ & 21 & 1.92 & $0.91-4.05$ \\
Non participants & 105 & 15 & 2.14 & $1.03-4.42$ & 5 & 1.5 & $0.44-4.83$ & 16 & 4.44 & $1.97-10.06$ \\
\hline
\end{tabular}

The distribution in high-risk and low-risk groups based on the health profile seemed, at group level, to be able to predict a significant higher incidence of CVD and cancer, and a non-significant higher incidence of total mortality, in the high-risk group in comparison with the low-risk group. The baseline non-participant group had a higher incidence of CVD, and a higher mortality than the low-risk group. Other studies have also shown that non-participants have a higher morbidity and mortality than participants [28]-[30]. In our earlier study of the baseline nonparticipant group this group could be divided into three different groups [11]. Those men who did not participate because they had already taken part in a similar health examination, those who already had frequent contacts with health care because if different diseases, and those who were not interested [11]. It is reasonable to think that the higher morbidity from CVD and mortality in the non-participant group can be linked primarily to these last two groups.

In most studies with long term follow-up the study population is 40 years and older at baseline. There are some examples where the study population is younger and single risk factors can predict CVD. In the Chicago Heart Association Detection Project in Industry blood pressure was related to mortality in CVD after 25 years [18]. In a study of three cohorts serum cholesterol had a long time relationship to CVD and all-cause mortality [19].

The SCORE-model based on age, gender, serum cholesterol, systolic blood pressure and smoking is designed to predict risk for mortality in CVD in 10 years for people 40 to 65 years [9]. This model was compared with the Framingham risk score and WHO/ISH model in Asian population 40 - 65 years, and was considered suitable to identify high CVD risk [31]. The SCORE-model is also compared to a Swedish consultation-based method without laboratory examinations on a population 40 - 59 years with equal result [32]. An aim for a future study can be to compare our health profile with the SCORE-model.

To our knowledge there are few examples of health prediction instruments for mortality of both cancer and CVD. The computer based Real Age is one example capable to predict mortality both for cancer and CVD [33]. In Real Age people could register health habits, family history, serum cholesterol, blood pressure and several psychosocial data. The data used in the Real Age register are similar to those in our health profile.

The strength in our study is the long follow-up time as well as the high participation rate among those who were invited. The limitations are lack of values for blood tests and blood pressures for those who were not invited, who also self-reported their own measurements of weight, height, and waist and hip circumferences. These data were thus not standardized according to the measurements that the nurses performed of the participants at the health care center. In spite of this we consider the self-reported data useful, and can be included in the data analyses. The Real Age register is also based on self-reported data [33]. There is always a risk for participation bias in follow-up studies. The high participation rate in our study and that those who were not invited were sent a postal questionnaire and asked to measure their weight, length, waist and hip circumferences are assumed to reduce the risk for participation bias. Another method to improve participation rate is to offer home visits to non-participants, as was done in the 32-year follow-up of the population study of women in Gothenburg [34].

\section{Conclusion}

In conclusion this study shows that it was possible to organize and carry out a long-term follow-up study, of this at baseline relative young group of men, in primary health care with a high participation rate. The categorization of the participants in high-risk and low-risk groups from values in the health profile could predict the incidence of CVD and cancer after 24 years of follow-up. Concerning lifestyle factors smoking and LTPA had decreased. Alcohol consumption had increased but from a relatively low level. Biological risk markers, except diastolic blood pressure, deteriorated significantly with age. 


\section{Acknowledgements}

This study was supported by grants from the Medical Research Council of Southeast Sweden (FORSS) and Futurum County Council of Jönköping Sweden.

\section{Ethical Approval}

The study was approved by the Regional Ethical Review Board in Linköping (Dnr M167-09).

\section{Declaration of Interest}

The authors report no conflict of interest. The authors alone are responsible for the content and writing of the paper.

\section{References}

[1] Sveriges Officiella Statistik. Statistik - Hälso- och Sjukvård. Dödsorsaker 2008. [Official Statistics of Sweden. Statistics - Health and Medical Care. Causes of Death 2008]. English Summery Stockholm: Socialstyrelsen; 2010.

[2] La Vecchia, C., Levi, F., Lucchini, F., et al. (1998) Trends in Mortality from Major Diseases in Europe, 1980-1993. European Journal of Epidemiology, 14, 1-8. http://dx.doi.org/10.1023/A:1007440201137

[3] The European Health Report (2012)

[4] Yusuf, S., Hawken, S., Ounpuu, S., et al. (2004) Effect of Potentially Modifiable Risk Factors Associated with Myocardial Infarction in 52 Countries (the INTERHEART Study): Case-Control Study. Lancet, 364, 937-952. http://dx.doi.org/10.1016/S0140-6736(04)17018-9

[5] O’Donnell, M.J., Xavier, D., Liu, L., et al. (2010) Risk Factors for Ischaemic and Intracerebral Haemorrhagic Stroke in 22 Countries (the INTERSTROKE Study): A Case-Control Study. Lancet, 376, 112-123. http://dx.doi.org/10.1016/S0140-6736(10)60834-3

[6] Coyle, Y.M. (2009) Lifestyle, Genes, and Cancer. Methods in Molecular Biology, 472, 25-56. http://dx.doi.org/10.1007/978-1-60327-492-0_2

[7] Khan, N., Afaq, F. and Mukhtar, H. (2010) Lifestyle as Risk Factor for Cancer: Evidence from Human Studies. Cancer Letters, 293, 133-143. http://dx.doi.org/10.1016/j.canlet.2009.12.013

[8] Carlsson, A.C., Wandell, P.E., Gigante, B., et al. (2013) Seven Modifiable Lifestyle Factors Predict Reduced Risk for Ischemic Cardiovascular Disease and All-Cause Mortality Regardless of Body Mass Index: A Cohort Study. International Journal of Cardiology, 168, 946-952.

[9] Conroy, R.M., Pyorala, K., Fitzgerald, A.P., et al. (2003) Estimation of Ten-Year Risk of Fatal Cardiovascular Disease in Europe: the SCORE Project. European Heart Journal, 24, 987-1003. http://dx.doi.org/10.1016/S0195-668X(03)00114-3

[10] Wilhelmsen, L., Wedel, H., Conroy, R., et al. (2004) The Swedish SCORE Chart for Cardiovascular Risk. Better Possibilities for Prevention of Cardiovascular Diseases. Lakartidningen, 101, 1798-801.

[11] Persson, L.G., Lindström, K., Lingfors, H. and Bengtsson, C. (1994) A Study of Men Aged 33-42 in Habo, Sweden with Special Reference to Cardiovascular Risk Factors. Design, Health Profile and Characteristics of Participants and Non-Participants. Scandinavian Journal of Social Medicine, 22, 264-272.

[12] Persson, L.G., Lindström, K., Lingfors, H., Bengtsson, C. and Lissner, L. (1998) Cardiovascular Risk during Early Adult Life. Risk Markers among Participants in "Live for Life" Health Promotion Programme in Sweden. Journal of Epidemiology \& Community Health, 52, 425-432. http://dx.doi.org/10.1136/jech.52.7.425

[13] Lingfors, H., Lindström, K., Persson, L.G., Bengtsson, C., Lissner, L., Ellegård, L. and Andersson, H.A. (1994) Evaluation of a Pedagogic Dietary Questionnaire Aimed for Health Surveys. Scandinavian Journal of Nutrition, 38, 106111.

[14] Doll, R., Peto, R., Boreham, J. and Sutherland, I. (2004) Mortality in Relation to Smoking: 50 Years' Observations on Male British Doctors. BMJ, 328, 1519. http://dx.doi.org/10.1136/bmj.38142.554479.AE

[15] Clarke, R., Emberson, J., Fletcher, A., Breeze, E., Marmot, M. and Shipley, M.J. (2009) Life Expectancy in Relation to Cardiovascular Risk Factors: 38 Year Follow-Up of 19,000 Men in the Whitehall Study. BMJ, 339, b3513. http://dx.doi.org/10.1136/bmj.b3513

[16] Holme, I., Tonstad, S., Sogaard, A.J., Lund Larsen, P.G. and Haheim, L.L. (2007) Leisure Time Physical Activity in Middle Age Predicts the Metabolic Syndrome in Old Age: Results of a 28-Year Follow-Up of Men in the Oslo Study. BMC Public Health, 7, 154. http://dx.doi.org/10.1186/1471-2458-7-154 
[17] Juonala, M., Viikari, J.S., Hutri-Kahonen, N., Pietikainen, M., Jokinen, E., Taittonen, L., et al. (2004) The 21-Year Follow-Up of the Cardiovascular Risk in Young Finns Study: Risk Factor Levels, Secular Trends and East-West Difference. Journal of Internal Medicine, 255, 457-468. http://dx.doi.org/10.1111/j.1365-2796.2004.01308.x

[18] Miura, K., Daviglus, M.L., Dyer, A.R., Liu, K., Garside, D.B., Stamler, J. and Greenland, P. (2001) Relationship of Blood Pressure to 25-Year Mortality Due to Coronary Heart Disease, Cardiovascular Diseases, and All Causes in Young Adult Men: The Chicago Heart Association Detection Project in Industry. Archives of Internal Medicine, 161, 1501-1508. http://dx.doi.org/10.1001/archinte.161.12.1501

[19] Stamler, J., Daviglus, M.L., Garside, D.B., Dyer, A.R., Greenland, P. and Neaton, J.D. (2000) Relationship of Baseline Serum Cholesterol Levels in 3 Large Cohorts of Younger Men to Long-Term Coronary, Cardiovascular, and All-Cause Mortality and to Longevity. JAMA, 284, 311-318. http://dx.doi.org/10.1001/jama.284.3.311

[20] Saltin, B. and Grimby, G. (1968) Physiological Analysis of Middle-Aged and Old Former Athletes. Comparison with Still Active Athletes of the Same Ages. Circulation, 38, 1104-1115. http://dx.doi.org/10.1161/01.CIR.38.6.1104

[21] Persson, L.G., Lindström, K. and Bengtsson, C. (1994) Oral Glucose Tolerance and Its Relationship to Overweight and Other Cardiovascular Risk Factors in Men Aged 33-42. A Study in the Community of Habo, Sweden. Scandinavian Journal of Primary Health Care, 12, 261-268. http://dx.doi.org/10.3109/02813439409029251

[22] Persson, L.G., Lindström, K., Lingfors, H. and Bengtsson, C. (1996) Results from an Intervention Programme Dealing with Cardiovascular Risk Factors. Experiences from a Study of Men Aged 33-42 in Habo, Sweden. Scandinavian Journal of Primary Health Care, 14, 184-192. http://dx.doi.org/10.3109/02813439609024175

[23] Svensson, E. (1998) Ordinal Invariant Measures for Individual and Group Changes in Ordered Categorical Data. Statistics in Medicine, 17, 2923-2936. http://dx.doi.org/10.1002/(SICI)1097-0258(19981230)17:24<2923::AID-SIM104>3.0.CO;2-\#

[24] Bopp, M., Braun, J., Gutzwiller, F. and Faeh, D., for the Swiss National Cohort Study Group (2012) Health Risk or Resource? Gradual and Independent Association between Self-Rated Health and Mortality Persists over 30 Years. PLoS ONE, 7, e30795. http://dx.doi.org/10.1371/journal.pone.0030795

[25] Latham, K. and Peek, C.W. (2013) Self-Rated Health and Morbidity Onset among Late Midlife US Adults. The Journals of Gerontology Series B: Psychological Sciences and Social Sciences, 68, 107-116. http://dx.doi.org/10.1093/geronb/gbs104

[26] Clarke, R., Breeze, E., Youngman, L., Sherliker, P., Bell, P., Shah, S., et al. (2000) Re-Survey of the Whitehall Study of London Civil Servants: Changes in Risk Factors for Cardiovascular Disease during 29 Years of Follow-Up. Journal of Cardiovascular Risk, 7, 251-257.

[27] Welin, L., Adlerberth, A., Caidahl, K., Eriksson, H., Hansson, P.-O., Johansson, S., et al. (2008) Prevalence of Cardiovascular Risk Factors and the Metabolic Syndrome in Middle-Aged Men and Women in Gothenburg, Sweden. BMC Public Health, 8, 403. http://dx.doi.org/10.1186/1471-2458-8-403

[28] Rosengren, A., Wilhelmsen, L., Berglund, G. and Elmfeldt, D. (1987) Non-Participation in a General Population Study of Men, with Special Reference to Social and Alcoholic Problems. Acta Medica Scandinavica, 221, 243-251. http://dx.doi.org/10.1111/j.0954-6820.1987.tb00890.x

[29] Wilhelmsen, L., Ljungberg, S., Wedel, H. and Werkö, L. (1976) A Comparison between Participants and Non-Participants in a Primary Preventive Trial. Journal of Chronic Diseases, 29, 331-339. http://dx.doi.org/10.1016/0021-9681(76)90093-X

[30] Larsen, S.B., Dalton, S.O., Schuz, J., Christensen, J., Overvad, K., Tjønneland, A., et al. (2012) Mortality among Participants and Non-Participants in a Prospective Cohort Study. European Journal of Epidemiology, 27, 837-845. http://dx.doi.org/10.1007/s10654-012-9739-x

[31] Selvarajah, S., Kaur, G., Haniff, J., Cheong, K.C., Hiong, T.G., van der Graaf, Y. and Bots, M.L. (2014) Comparison of the Framingham Risk Score, SCORE and WHO/ISH Cardiovascular Risk Prediction Models in an Asian Population. International Journal of Cardiology, 176, 211-218. http://dx.doi.org/10.1016/j.ijcard.2014.07.066

[32] Petersson, U., Östgren, C.J., Brudin, L. and Nilsson, P.M. (2009) A Consultation-Based Method Is Equal to SCORE and an Extensive Laboratory-Based Method in Predicting Risk of Future Cardiovascular Disease. European Journal of Cardiovascular Prevention \& Rehabilitation, 16, 536-540. http://dx.doi.org/10.1097/HJR.0b013e32832b1833

[33] Hobbs, W.R. and Fowler, J.H. (2014) Prediction of Mortality Using On-Line, Self-Reported Health Data: Empirical Test of the Real Age Score. PLoS ONE, 9, e86385. http://dx.doi.org/10.1371/journal.pone.0086385

[34] Lissner, L., Skoog, I., Andersson, K., Beckman, N., Sundh, V., Waern, M., et al. (2003) Participation Bias in Longitudinal Studies: Experience from the Population Study of Women in Gothenburg, Sweden. Scandinavian Journal of Primary Health Care, 21, 242-247. http://dx.doi.org/10.1080/02813430310003309-1693 